\title{
Nanostructured Ti Consolidated via Spark Plasma Sintering
}

\author{
OSMAN ERTORER, TROY D. TOPPING, YING LI, WES MOSS, \\ and ENRIQUE J. LAVERNIA
}

\begin{abstract}
Cryomilled nanocrystalline commercially pure (CP)-Ti powders were spark plasma sintered (SPS) using different process parameters (heating rate, temperature, pressure, and dwell time) to study densification, microstructure, and mechanical behavior. The results were rationalized on the basis of the relevant literature and experimental results, and they reveal a strong dependence on SPS parameters. An interesting finding was that the measured high ductility was accompanied by a moderate strength (yield strength $[\mathrm{YS}]=770 \mathrm{MPa}$, ultimate tensile strength $[\mathrm{UTS}]=840 \mathrm{MPa}$ with $\sim 27$ pct elongation to failure). The combinations of microstructure and mechanical response were attributed to the multistep processing at different temperature ranges as well as to the presence of interstitial solutes.
\end{abstract}

DOI: $10.1007 / \mathrm{s} 11661-010-0499-5$

(C) The Author(s) 2010. This article is published with open access at Springerlink.com

\section{INTRODUCTION}

TITANIUM alloys are widely used as structural materials especially for aerospace, marine, and biomedical applications due to their high specific strength, hightemperature stability, excellent corrosion resistance and biocompatibility. ${ }^{[1-3]}$ Even though many alpha, nearalpha, beta, and alpha-beta alloys are available and widely used for different applications, certain requirements demand the use of commercially pure $(\mathrm{CP})$ grades of titanium. As an example, the superior corrosion resistance of $\mathrm{CP}-\mathrm{Ti}$, as compared to that of other $\mathrm{Ti}$ alloys renders it the preferred material for applications in reaction vessels and heat exchangers. ${ }^{[1,2,4]} \mathrm{CP}-\mathrm{Ti}$ also has distinct advantages as a biomedical implant material because it does not contain elements such as $\mathrm{Al}$ and $\mathrm{V}$, which are reported to cause adverse biological reactions. ${ }^{[5,6]}$ However, CP-Ti grades exhibit relatively lower strength as compared to other commercially available $\mathrm{Ti}$ alloys, and this limits their use for many other applications. ${ }^{[1]}$

In recent years, studies have reported improvements in mechanical properties for ultrafine-grained (UFG) and nanostructured (NS) CP-Ti; particularly noteworthy are those processed via severe plastic deformation techniques. ${ }^{[7-11]}$ This trend is illustrated by reports of CP-Ti with combinations of high tensile strength and good ductility (900-1500 MPa ultimate tensile strength [UTS] and 6-25 pct elongation to failure) as reported in different studies when processed via high-pressure torsion, ${ }^{[9]}$ equal-channel angular pressing (ECAP), ${ }^{[7,12]}$ and cryomilling. ${ }^{[13,14]}$ For example, Semenova et al. ${ }^{[7]}$ reported up to $1150 \mathrm{MPa}$ room temperature tensile

OSMAN ERTORER, Graduate Student Researcher, TROY D. TOPPING, Graduate Student Researcher, YING LI, Postdoctoral Researcher, and ENRIQUE J. LAVERNIA, Full-Time Professor, are with the University of California, Davis, Davis, CA 95616. Contact e-mail: oertorer@ucdavis.edu. WES MOSS, Senior Manager of Materials Technology, is with Toyota Racing Development, Costa Mesa, CA 92626.

Manuscript submitted June 3, 2010

Article published online November 5, 2010 yield strength (YS) and $1240 \mathrm{MPa}$ UTS with a tensile elongation value of 11 pct, using ECAP followed by a heat treatment step.

The microstructure and mechanical behavior of cryomilled CP-Ti was studied previously by Ertorer et al. ${ }^{[13,14]}$ In these studies, balanced combinations of strength and ductility were reported. Also in these studies, quasi-isostatic (QI) forging was used as a consolidation and secondary deformation method. Specifically, a multistep approach was adopted in this study and involved cryomilling, blending with micron-sized powders (to generate a multiscale microstructure), ${ }^{[15]}$ hot vacuum degassing, and QI forging produced materials with a multimodal grain size distribution. In roomtemperature tensile tests, a YS of $840 \mathrm{MPa}$, a UTS of $902 \mathrm{MPa}$, and an elongation to failure value of $27.5 \mathrm{pct}$ were measured for these samples. More detailed information related to cryomilled $\mathrm{Ti}$ powders and bulk materials is available in related publications by Sun et $a l .{ }^{[16,17]}$ and Ertorer et al. ${ }^{[14]}$

In view of the aforementioned results, the objective of the present work is to investigate the consolidation behavior, microstructure evolution and mechanical behavior of cryomilled CP-Ti powders consolidated via the spark plasma sintering (SPS) technique. In the last- two decades, SPS has emerged as an interesting consolidation approach given its reported ability to densify metal and ceramic powders fully in a short time interval, thereby helping retain the starting microstructure. ${ }^{[18-25]}$ SPS can be grouped as one of various field activated sintering methods that are commercially available, in which a pulsed electric current is passed through the powder sample in a graphite die pressed to desired pressure between two electrodes. ${ }^{[18,26,27]}$ SPS has emerged as a possible consolidation pathway for NS materials given the shorter sintering times involved, which reportedly limit the grain growth, relative to the longer time exposures typically involved in conventional methods, such as hot pressing (HP) and hot isostatic pressing. ${ }^{[19,20,26,28]}$ Interestingly, however, and despite numerous scientific studies completed with different 
materials, the underlying mechanisms that govern sintering during SPS are poorly understood. ${ }^{[20,27,29]}$ The main characteristics of the SPS process can be listed as: (1) a relatively high heating rate (typically $50 \mathrm{~K} / \mathrm{min}$ to $200 \mathrm{~K} / \mathrm{min}, 1000 \mathrm{~K} / \mathrm{min}\left[50^{\circ} \mathrm{C} / \mathrm{min}\right.$ to $200^{\circ} \mathrm{C} / \mathrm{min}, 1000$ ${ }^{\circ} \mathrm{C} / \mathrm{min}$ ] maximum), (2) application of a uniaxial pressure ( 100 MPa maximum for a graphite die), and (3) effect of the current (in the order of $10^{3}$ Amps depending on the die size, heating rate, temperature, and material). ${ }^{[20,26,27]}$ However, the precise influence of the magnitude of these parameters on microstructure evolution depends strongly on materials chemistry, as documented in the literature. ${ }^{[19,26,27,29]}$

A review of the published literature shows that SPS has been applied to consolidate cryomilled $\mathrm{Al}^{[30]}$ and $\mathrm{Ni}^{[31]}$ alloys, but literature on SPS-consolidated cryomilled CP-Ti is not available. Accordingly, in the current study, powder CP-Ti samples from a predetermined mixture of cryomilled NS + as-received micron-sized powders were SPS processed using different heating rates $\left(50 \mathrm{~K} / \mathrm{min}\right.$ and $100 \mathrm{~K} / \mathrm{min}\left[50^{\circ} \mathrm{C} / \mathrm{min}\right.$ and $\left.100{ }^{\circ} \mathrm{C} / \mathrm{min}\right]$ ), sintering temperatures $(1023 \mathrm{~K}, 1073 \mathrm{~K}, 1123 \mathrm{~K}$, and $1173 \mathrm{~K}\left[750{ }^{\circ} \mathrm{C}, 800{ }^{\circ} \mathrm{C}, 850{ }^{\circ} \mathrm{C}\right.$, and $\left.900^{\circ} \mathrm{C}\right]$ ), dwell times ( 3 minutes and 5 minutes) and pressures (40 MPa and $80 \mathrm{MPa}$ ) to investigate the densification response, microstructure evolution, and mechanical behavior. The goal of the current study is to enhance our fundamental understanding of the influence of SPS parameters on final density, grain size, microhardness, and room temperature tensile behavior. The current results are also compared to previous data obtained from cryomilled and QI-forged samples of CP-Ti. ${ }^{[13,32]}$

\section{EXPERIMENTAL}

CP-Ti (grade II) powders (Advanced Specialty Metals, Inc., Nashua, NH) with an average particle size of $55 \mu \mathrm{m}$, grain size typically in the $1-30 \mu \mathrm{m}$ interval, and a chemical composition (in wt pct) of 0.19 pct $\mathrm{O}$, 0.0017 pct N, 0.003 pct $\mathrm{C}$, and 0.013 pct Fe were used as starting materials for the cryomilling experiments. A $1-\mathrm{kg}$ batch of powders was cryomilled for 8 hours in a liquid argon environment $(183 \pm 5 \mathrm{~K})\left(90^{\circ} \mathrm{C}\right)$ using a modified Union Process 1-S Szegvari (Union Process, Akron, OH) type attritor (impeller rotation speed of $180 \mathrm{rpm}$ ), a stainless steel tank, and $30 \mathrm{~kg}$ stainless steel balls. Carbon black (C, 99.9+ pct, acetylene) (0.4 wt pct) was used as a process control agent (PCA) to improve powder yield. ${ }^{[33]}$ Elemental chemical analyses of both cryomilled powders and SPS processed bulk samples for $\mathrm{O}, \mathrm{C}, \mathrm{N}, \mathrm{H}$, and $\mathrm{Fe}$ were carried by a commercial laboratory (Luvak, Inc., Boylston, MA).

The cryomilled powders were annealed for 1 hour at different temperatures in closed stainless steel tubing. $\mathrm{X}$-ray diffraction (XRD) experiments were made using a Scintag XDS 2000 (Scintag Inc., Cupertino, CA) diffractometer $\left(\mathrm{Cu} \mathrm{K} \mathrm{K}_{\alpha}\right)$ for phase identification and crystallite size calculations.

The as-processed cryomilled powders were blended with micron-sized, as-received powders (70 pct cryomilled +30 pct as-received, wt/wt) using a V-shape blender for 10 hours in an argon environment. The selection of a 70 pct cryomilled +30 pct as-received mixture was motivated by numerous reports on improved ductility in bimodal and multimodal metals, ${ }^{[15,34-38]}$ as well as earlier experiments on QI-forged cryomilled Ni and $\mathrm{Ti}^{[13,14,39,40]}$ The blended powders were degassed in a closed stainless steel can under vacuum $\left(\sim 10^{-3} \mathrm{~Pa}\right)$ at $623 \mathrm{~K}\left(350^{\circ} \mathrm{C}\right)$ to eliminate moisture and other volatile species using a Varian Turbo-V 70D (Varian Inc., Santa Clara, CA) turbo molecular pump equipped with a Terranova Model 934 vacuum gage controller (Duniway Inc., Mountain View, CA) and a tube furnace. The degassed can was opened and powders were stored in an argon glove box until SPS processing to minimize possible atmospheric contamination.

SPS experiments were carried using an SPS-825S DR. SINTER apparatus (SPS Syntex Inc., Japan) under a vacuum condition ( $\sim 6-8 \mathrm{~Pa})$. Approximately 30 grams of the powder blend was loaded to a high-density graphite die with $50 \mathrm{~mm}$ internal diameter, immediately prior to each experiment. Thin graphite foils were placed between powders and graphite die surfaces to prevent welding and obtain a more uniform current flow. The desired sintering pressure was applied prior to heating and maintained until the end of sintering. A total of 9 samples were sintered using experimental parameters as shown in Table I). Accordingly different heating rates $\left(50 \mathrm{~K} / \mathrm{min}\right.$ and $100 \mathrm{~K} / \min \left[50^{\circ} \mathrm{C} / \min\right.$ and $\left.\left.100^{\circ} \mathrm{C} / \mathrm{min}\right]\right)$, sintering temperatures $(1023 \mathrm{~K}, 1073 \mathrm{~K}, 1123 \mathrm{~K}$, and $1173 \mathrm{~K}\left[750{ }^{\circ} \mathrm{C}, 800{ }^{\circ} \mathrm{C}, 850{ }^{\circ} \mathrm{C}\right.$, and $\left.900{ }^{\circ} \mathrm{C}\right]$ ), dwell times ( 3 minutes and 5 minutes), and pressures (40 MPa and $80 \mathrm{MPa}$ ) were used. The SPS samples were ground and polished to fine and graphite-free surfaces prior to density measurements and microhardness testing.

Archimedes' method was used for density measurements. The samples were soaked in a 70 pct water +30 pct methanol ( $\mathrm{vol} / \mathrm{vol})$ solution prior to measurement in water to eliminate any air bubbles present. Microhardness studies were carried using a Buehler Micromet 2004 Vickers (Buehler Inc., Lake Bluff, IL) hardness tester at a $9807 \mathrm{mN}$ load. Each sample was measured at 10 different locations to calculate average microhardness.

Room-temperature tensile behavior of the specimens was determined at a constant strain rate of $10^{-3} \mathrm{~s}^{-1}$, and strain rate sensitivity was measured via strain rate jump

Table I. List of SPS Samples with Corresponding Process Parameters

\begin{tabular}{lcccc}
\hline Sample \# & $\begin{array}{c}\text { Heating } \\
\text { Rate (C/min) }\end{array}$ & $\begin{array}{c}\text { Dwell } \\
\text { Temp [C] }\end{array}$ & $\begin{array}{c}\text { Dwell } \\
\text { Time (min) }\end{array}$ & $\begin{array}{c}\text { Pressure } \\
(\mathrm{MPa})\end{array}$ \\
\hline 1 & 50 & 750 & 5 & 80 \\
2 & 50 & 800 & 5 & 80 \\
3 & 50 & 850 & 5 & 80 \\
4 & 50 & 900 & 5 & 80 \\
5 & 50 & 850 & 3 & 80 \\
6 & 50 & 850 & 5 & 40 \\
7 & 100 & 850 & 3 & 80 \\
8 & 50 & 850 & 3 & 40 \\
9 & 100 & 850 & 5 & 40 \\
\hline
\end{tabular}


testing at strain rates of $10^{-5} \mathrm{~s}^{-1}, 10^{-4} \mathrm{~s}^{-1}, 10^{-3} \mathrm{~s}^{-1}$, $10^{-2} \mathrm{~s}^{-1}$ using an Instron 8801 (Instron Inc., Norwood, MA) universal testing machine equipped with a video extensometer and Blue Hill software (Norwood, MA). Flat dogbone test specimens with $\sim 10 \mathrm{~mm}$ gage length, 3-3.5 mm width, and $2.5-3 \mathrm{~mm}$ height were electrodischarge machined (EDM) by Toyota Racing Development (Costa Mesa, CA).

Remnant pieces were used for chemical and microstructure analysis. Accordingly, thin foils for transmission electron microscopy (TEM) analysis were prepared via mechanical grinding (to $80 \mu \mathrm{m}$ thickness), dimpling (to 10-20 $\mu \mathrm{m}$ center thickness), and ion milling with $4 \mathrm{kV}$ Ar ions. The TEM observations were made using a Philips CM12 microscope operated at $100 \mathrm{kV}$ and a JEOL 2500SE microscope operating at $200 \mathrm{kV}$.

\section{RESULTS AND DISCUSSION}

\section{A. Cryomilled Powders}

The chemical analysis results show that the 8-hour cryomilled powders contain 0.252 pet $\mathrm{O}, 0.20$ pet $\mathrm{N}$, 0.26 pct $\mathrm{C}, 0.0056$ pct $\mathrm{H}$, and 0.087 pct Fe by weight. The amounts of $\mathrm{O}, \mathrm{N}, \mathrm{C}$, and $\mathrm{Fe}$ are found to be significantly increased as compared to the composition of the starting powders. Powder contamination is an inherent characteristic of cryomilling, and it may arise either from the processing media or from the atmosphere. ${ }^{[14,16,33,41]}$ Carbon black, used as PCA, represents the origin of increased $\mathrm{C}$ content, whereas the steel milling media is the source for $\mathrm{Fe}$ contamination. The increased amounts of $\mathrm{N}$ and $\mathrm{O}$ are attributable to atmospheric contamination during powder handling and transport prior to chemical analysis. $\mathrm{HCP} \mathrm{Ti}$ is known to have a high affinity for $\mathrm{O}$ and $\mathrm{N}$ atoms, which can be accommodated as interstitial solutes (max. $\sim 2.6$ wt. pct $\mathrm{O}$, and 8 wt. pct $\mathrm{N}$ ), and possible stable oxides/nitrides (TiO, $\mathrm{Ti}_{2} \mathrm{O}_{3}, \quad \mathrm{Ti}_{3} \mathrm{O}_{5}, \quad \mathrm{TiO}_{2}$, and TiN). ${ }^{[1,2,16,42]}$ No evidence supporting the presence of second-phase particles was found in TEM and XRD studies, and therefore, $\mathrm{N}$ and $\mathrm{O}$ atoms are deduced to be present as interstitial and grain boundary solute atoms. The details related to $\mathrm{N}$ and $\mathrm{O}$ diffusion, and the formation energies of second phases are presented elsewhere. ${ }^{[42]}$

Cryomilled $\mathrm{Ti}$ powders are even more sensitive to atmospheric contamination due to increased grain boundary area and dislocation density, ${ }^{[41]}$ which are known to stimulate rapid diffusion mechanisms such as grain boundary diffusion and pipe diffusion. ${ }^{[43-45]}$ Grain boundaries and dislocations accommodate solute atoms more readily as a result of their higher surface energy. ${ }^{[46,47]}$ The results are also consistent with earlier studies on cryomilled $\mathrm{Ti}^{[17]} \mathrm{Al},{ }^{[48]}$ and $\mathrm{Ni}^{[49]}$ alloys, as well as general literature on the Ti structure. ${ }^{[2,12,42]}$

The average grain size of 8 hours of cryomilled powders was calculated to be $19 \mathrm{~nm}$ from the XRD peak broadening data using the single-line-approximation analysis developed by De Keijser et al. ${ }^{[50]}$ Approximating the grain size broadening profiles by a Cauchy function, the grain size $(D)$ can be estimated from each diffraction peak with diffraction angle $\theta$ by:

$$
D=\frac{k \lambda}{\beta_{c}^{f} \cos \theta}
$$

where $\beta_{c}^{f}$ is the constituent Cauchy component.

The measured grain size is consistent with earlier cryomilled CP-Ti and grain size evolution models which, suggest that there is a minimum grain size is attainable during cryomilling. ${ }^{[51,52]}$ A dislocation model developed by Mohamed ${ }^{[51]}$ describes this minimum grain size (i.e., $d_{\text {min }}$ ) quantitatively, and it is based on a balance between dislocation generation, and recovery. Considering the rates of generation and recovery, $d_{\min }$ is given by:

$$
\frac{d_{\min }}{b}=\operatorname{Ae}^{\left(\frac{-\beta Q}{4 R T}\right)}\left(\frac{D_{\mathrm{PO}} G b^{2}}{v_{0} k_{\mathrm{B}} T}\right)^{0.25}\left(\frac{\gamma}{G b}\right)^{0.5}\left(\frac{G}{\sigma}\right)^{1.25}
$$

where $\mathrm{A}$ and $\beta$ are constants, $Q$ is self-diffusion activation energy, $b$ is the magnitude of the Burgers vector, $\mathrm{R}$ is the gas constant, $T$ is the absolute temperature, $D_{\mathrm{PO}}$ is the pipe-diffusion coefficient, $v_{0}$ is the initial dislocation velocity, $k_{\mathrm{B}}$ is Boltzmann's constant, $\gamma$ is the stacking fault energy, $G$ is the shear modulus, and $\sigma$ is the applied stress.

Despite the reported thermal stability of cryomilled CP-Ti powders, ${ }^{[17]}$ as documented in the literature, experiments were conducted in the current study to investigate the effects of carbon black used as PCA. The calculated grain sizes from XRD peak broadening profiles for corresponding annealing temperatures were plotted in Figure 1. As can be interpreted from the data, there is a reduction in grain size in the $673 \mathrm{~K}$ to $873 \mathrm{~K}$ $\left(400{ }^{\circ} \mathrm{C}\right.$ to $600{ }^{\circ} \mathrm{C}$ ) temperature range, which is similar to the previously reported results for liquid nitrogen cryomilled powders. This is attributable to the presence of a critical temperature range, where dislocation slip across interstitial solutes is thermally activated, as presented in earlier detailed studies. ${ }^{[42,53,54]}$ This is thought to cause a realignment of dislocations, forming a refined structure.

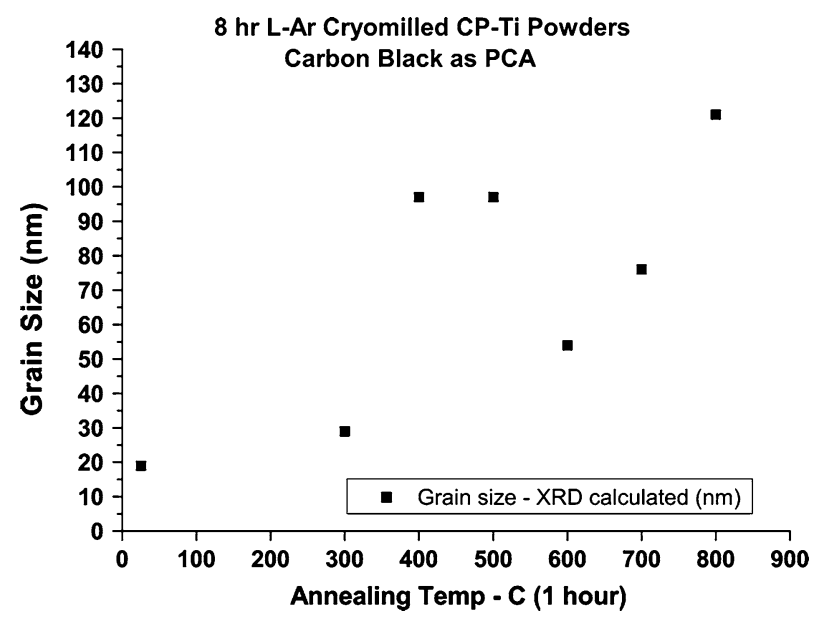

Fig. 1-Annealing temperature $v s$ grain size plot for $1 \mathrm{~h}$ annealed cryomilled powders. 
Table II. Density and Microhardness Measurement Results for SPS Samples

\begin{tabular}{llcc}
\hline Sample & $\begin{array}{c}\text { Density } \\
\left(\mathrm{g} / \mathrm{cm}^{3}\right)\end{array}$ & $\begin{array}{c}d / d_{\text {theoretical }} \\
(\mathrm{pct})\end{array}$ & $\begin{array}{c}\text { Average } \\
\text { Microhardness }(\mathrm{HV})\end{array}$ \\
\hline 1 & 4.4759 & 99.24 & 237 \\
2 & 4.4757 & 99.24 & 247 \\
3 & 4.4728 & 99.18 & 249 \\
4 & 4.4722 & 99.16 & 244 \\
5 & 4.4741 & 99.2 & 247 \\
6 & 4.4371 & 98.38 & 243 \\
7 & 4.4741 & 99.2 & 247 \\
8 & 4.4413 & 98.48 & 240 \\
9 & 4.424 & 98.09 & 240 \\
\hline
\end{tabular}

\section{B. Densification}

The measured densities and their density ratios (e.g., relative to theoretical density) for SPS samples are given in Table II. The most noteworthy finding from the density data is the positive effect of a higher applied pressure on densification. The results reveal that a density larger than 99 pct of the theoretical density of hcp Ti was achieved when $80 \mathrm{MPa}$ uniaxial pressure was applied during sintering. In contrast with this observation, however, the measured densities remained in $98 \mathrm{pct}$ to 99 pct interval when the applied pressure was $40 \mathrm{MPa}$. This finding is not surprising because the positive effect of a higher applied pressure on densification is a well-established phenomenon in powder metallurgy. ${ }^{[55,56]}$ In the relevant literature, mechanical and intrinsic effects of an applied pressure field on densification were reported. ${ }^{[55]}$ The mechanical effect is more direct as the pressure reduces the interparticle spacing and thereby enhances diffusion. Pressure also promotes the breakup and destruction of the agglomerate structure that evolves during cryomilling. The intrinsic contribution of pressure is related to the driving force for sintering. At the microscopic level, the driving force is capillary pressure associated with surface curvature of particles. In the case of HP, effective pressures at the initial $\left(P_{\mathrm{i}}\right)$ and final $\left(P_{\mathrm{f}}\right)$ stages of sintering are given by the following equations ${ }^{[55]}$ :

$$
P_{\mathrm{i}} \approx \frac{4 a^{2}}{\pi x^{2}} P_{\text {applied }}+\frac{\gamma_{\mathrm{s}}}{r} \text { and } P_{\mathrm{f}} \approx \frac{P_{\text {applied }}}{\rho}+\frac{2 \gamma_{\mathrm{s}}}{r}
$$

where $a$ is the particle radius, $x$ is the neck radius, $r$ is the radius of curvature of the neck surface, $\rho$ is the relative density of the compact, and $\gamma_{\mathrm{s}}$ is the surface energy. These equations assume a simple cubic packing of spherical particles, but here, the key term is the applied pressure, and it is directly proportional to the effective pressure for sintering (i.e., driving force).

The other SPS parameters, such as the heating rate, sintering temperature, and dwell time, were found to have no significant effect on densification when the applied pressure was $80 \mathrm{MPa}$. However, a higher heating rate $\left(100 \mathrm{~K} / \mathrm{min}\left[100{ }^{\circ} \mathrm{C} / \mathrm{min}\right]\right)$ was found to result in a slightly lower density (comparing sample \#6 and \#9) when the applied pressure was $40 \mathrm{MPa}$. The lower density attained at higher heating rates is attributable to premature necking possibly resulting from the formation of local hot spots and melting via arcing (i.e., dielectric breakdown) at the initial stages of heating. ${ }^{[23,28,57,58]}$ This premature necking is thought to be responsible for entrapment of porosities and, thereby, a lower final density. Even though the underlying mechanisms are not fully understood, the formation of a dielectric breakdown event at the interparticle spacing during field activated sintering processes has been previously mentioned in the literature. ${ }^{[28]}$ The localization and increase in magnitude of a dielectric breakdown event are both factors that are expected to be higher at lower applied pressures and higher heating rates during SPS processing. ${ }^{[59]} \mathrm{A}$ lower applied pressure provides smaller contact areas and larger spacing between individual particles, whereas a high heating rate requires a high applied current. For example, in the current study, even during the initial stages of processing (in the $298 \mathrm{~K}$ to $373 \mathrm{~K}\left[25^{\circ} \mathrm{C}\right.$ to $\left.100^{\circ} \mathrm{C}\right]$ interval) the measured maximum current for sample \#9 (pressure: $40 \mathrm{MPa}$, heating rate: $100 \mathrm{~K} / \mathrm{min}\left[100{ }^{\circ} \mathrm{C} / \mathrm{min}\right]$ ) was as high as $\sim 3000 \mathrm{Amps}$, whereas it was $\sim 1600$ Amps for samples \#6 and \#8 (pressure: $40 \mathrm{MPa}$, heating rate: $50 \mathrm{~K} / \mathrm{min}\left[50^{\circ} \mathrm{C} / \mathrm{min}\right]$ ).

\section{Microstructure}

Images of the SPS-processed sample microstructures (from sample \#4) are given in Figures 2(a) through (d). The general microstructure is characterized by coarsegrained and fine-grained regions, in agreement with multimodal material design (i.e., powder blending). As can be observed in the SEM micrograph (Figure 2(a)), the microstructure represents a size (i.e., grain diameter) distribution in the range of $200 \mathrm{~nm}$ to $40 \mu \mathrm{m}$. The grains characterized in the size range of $200 \mathrm{~nm}$ to $5 \mu \mathrm{m}$ are thought to originate from cryomilled powders, and larger grains observed are thought to originate from as-received powders. Another characteristic of the microstructures is the observed dislocation tangling near grain boundaries as represented in Figure 2(d). Formation of a dislocation-rich microstructure is characteristic to cryomilling. ${ }^{[16,41]}$ A similar microstructure was also reported for cryomilled and quasi-isostatic forged CP-Ti samples. ${ }^{[14]}$ The formation of such a microstructure is attributable to variations in dislocation - solute atom interactions at different temperature regimes. Conrad, ${ }^{[42]}$ in a review article, discussed the kinetics of dislocation-solute atom interactions, at a cryogenic temperature, at room temperature, and at an elevated temperature $\left(T>673 \mathrm{~K}\left[400^{\circ} \mathrm{C}\right]\right)$. Accordingly, at cryogenic temperatures, solute atoms act as strong obstacles for a dislocation motion that causes the formation of solute-rich dislocation arrays. During a consolidation step at elevated temperatures, this effect is removed and results in the alignment of dislocations forming new grain boundaries (at $\sim 673 \mathrm{~K}$ to $773 \mathrm{~K}\left(400{ }^{\circ} \mathrm{C}\right.$ to $\left.500{ }^{\circ} \mathrm{C}\right)$ ), and coarsening $\left(T>773 \mathrm{~K}\left[500{ }^{\circ} \mathrm{C}\right]\right)$. However, deformation at room temperature (e.g., tensile testing) caused a refinement (postmortem microstructure for sample \#5 is shown in Figure 3) due to the formation of dislocation networks. This is due to the re-establishment of the barrier effect of solute atoms, limiting prismatic dislocation slip. ${ }^{[42,54,60,61]}$ This effect is presumably not severe, as 


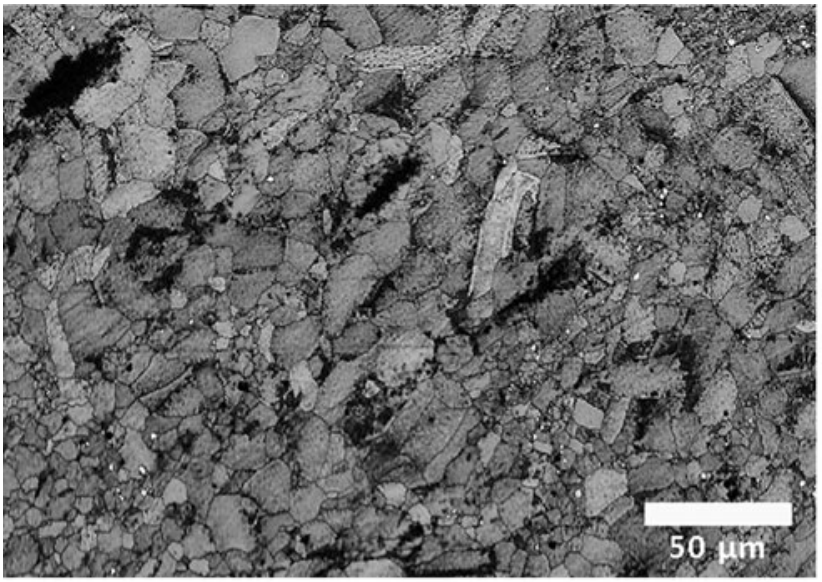

(a)

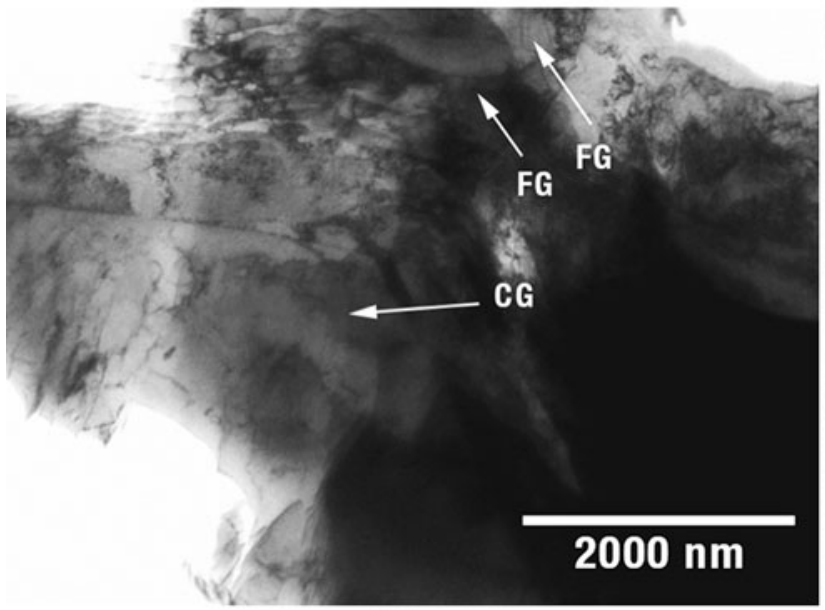

(b)

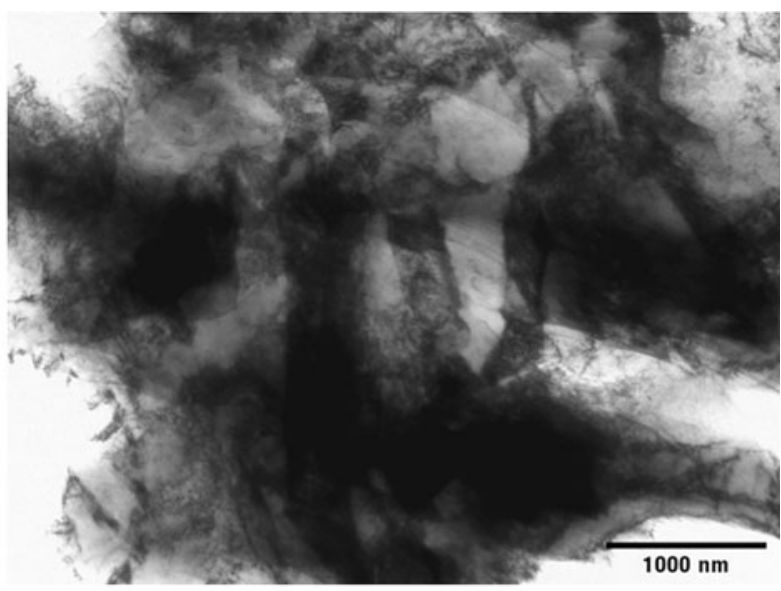

(c)

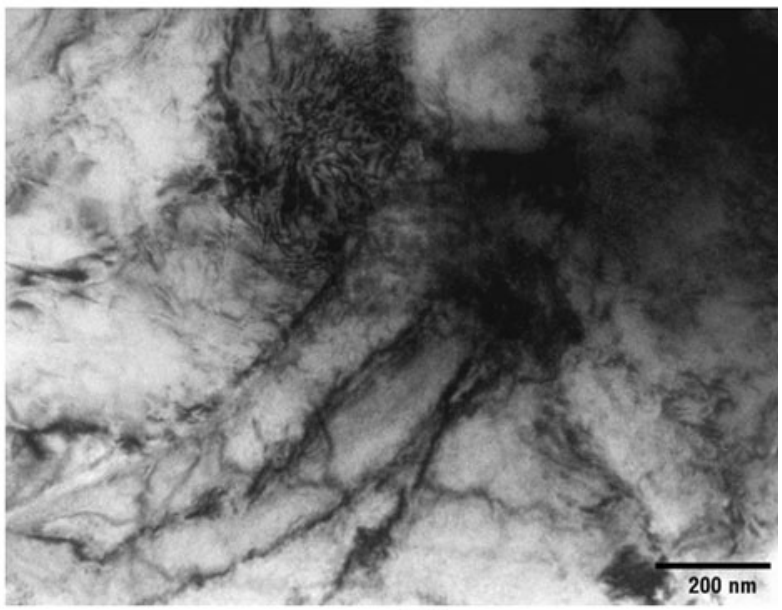

(d)

Fig. 2-Representative microstructure images from sample \#4 showing (a) SEM micrograph of general microstructure, (b) TEM of coarsegrained and fine-grained regions, $(c)$ details on fine-grained region, and $(d)$ dislocation tangling near grain boundary section.

it is at cryogenic temperatures but still effective enough to facilitate the dominant deformation mechanisms as will be discussed in the next section.

\section{Mechanical Behavior}

The mechanical behavior of the SPS-consolidated samples was evaluated on the basis of the microhardness and tensile testing results. It is noteworthy, despite a narrow distribution of measured microhardness values for different samples (in the 237-249 HV interval as presented in Table II), that the variations in measured tensile YS, UTS, and ductility (i.e., elongation to failure) were notably large as presented in Table III. Such an inconsistency between microhardness and tensile data is attributable to the presence of extrinsic and intrinsic structural differences (i.e., insufficient interparticle bonding for some samples and microstructural factors affecting deformation mechanism under tensile loading). ${ }^{[62,63]}$ The narrow distribution of microhardness is attributable to the similar chemical composition and average grain size of tested materials, where tensile behavior is thought to be dependent on a number of other factors, as mentioned previously.
Room-temperature stress-strain curves for specimens tested at a constant strain rate $\left(10^{-3} \mathrm{~s}^{-1}\right)$ are presented using a comparative approach in Figures 4 through 7. Samples \#1, \#2, \#3, and \#4 are compared in Figure 4 to reveal the isolated effect of sintering temperature (i.e., identical heating rate, pressure, and dwell time). Very close YS and UTS values were measured for these samples. However, not surprisingly, a higher sintering temperature effectively improved the ductility. Such behavior is attributable to weaker particle-particle interfaces for samples consolidated below $1123 \mathrm{~K}(850$ $\left.{ }^{\circ} \mathrm{C}\right)$. Sufficient interparticle bonding is a critical first step for attaining a good ductility for samples produced through powder metallurgy routes. ${ }^{[36]}$ Therefore, the high postnecking strain measured for sample \#4 is attributable to improved interparticle bonding that hinders crack propagation through particle boundaries. The retained strength at high temperatures is attributable to limited grain growth and UFG regions present as a result of short processing times for SPS. This is a wellestablished advantage of SPS process as illustrated by earlier studies. ${ }^{[18,21]}$

In Figures 5(a) and (b), the effect of applied pressure was compared for different samples using a similar 


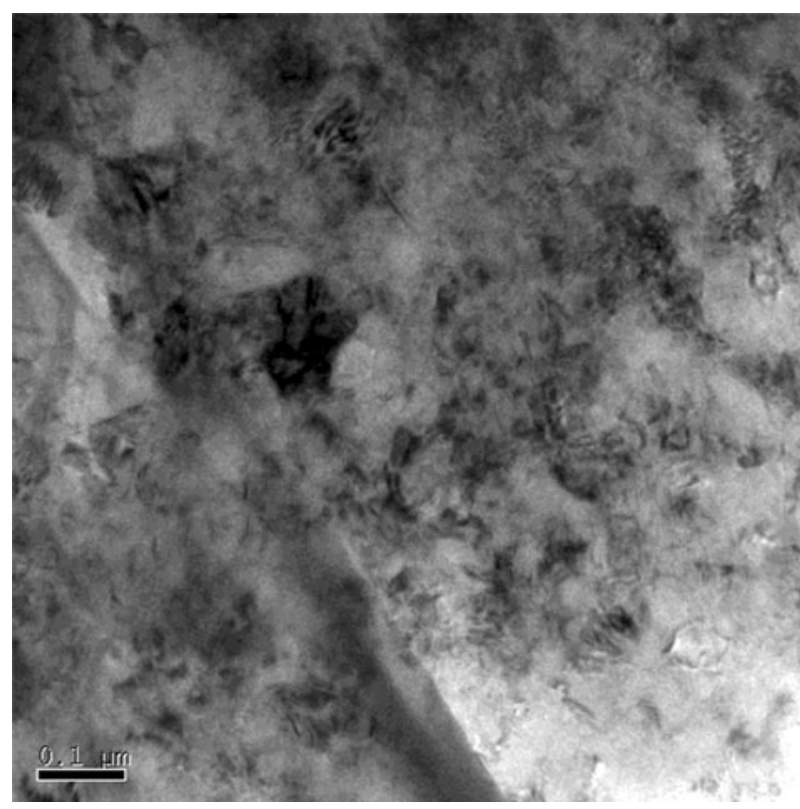

Fig. 3-A postmortem microstructure for sample \#5 showing the refined microstructure.

Table III. Tensile Properties of SPS Samples

\begin{tabular}{lccc}
\hline Sample \# & $\begin{array}{c}\text { Yield } \\
\text { Strength } \\
(\mathrm{MPa})\end{array}$ & $\begin{array}{c}\text { Ultimate } \\
\text { Tensile } \\
\text { Strength (MPa) }\end{array}$ & $\begin{array}{c}\text { Tensile Elongation } \\
\text { at Fracture (pct) }\end{array}$ \\
\hline 1 & 721 & 776 & 11.4 \\
2 & 704 & 758 & 8.3 \\
3 & 709 & 768 & 16.4 \\
4 & 706 & 776 & 29.3 \\
5 & 770 & 838 & 26.4 \\
6 & 710 & 775 & 14.4 \\
7 & 752 & 823 & 19 \\
8 & 698 & 758 & 14.4 \\
9 & 670 & 734 & 14.2 \\
\hline
\end{tabular}

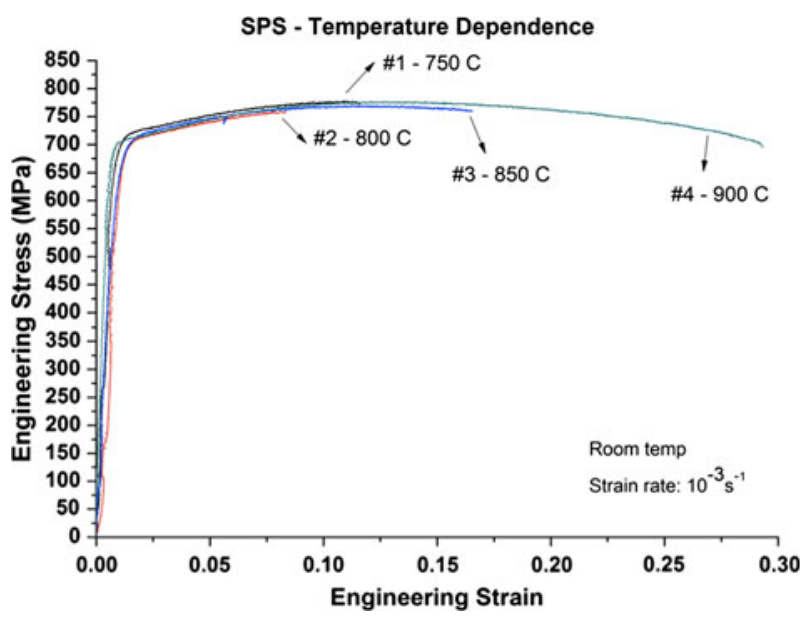

Fig. 4-Engineering stress-strain curves comparing \#1, \#2, \#3, and \#4 to reveal SPS temperature dependence.

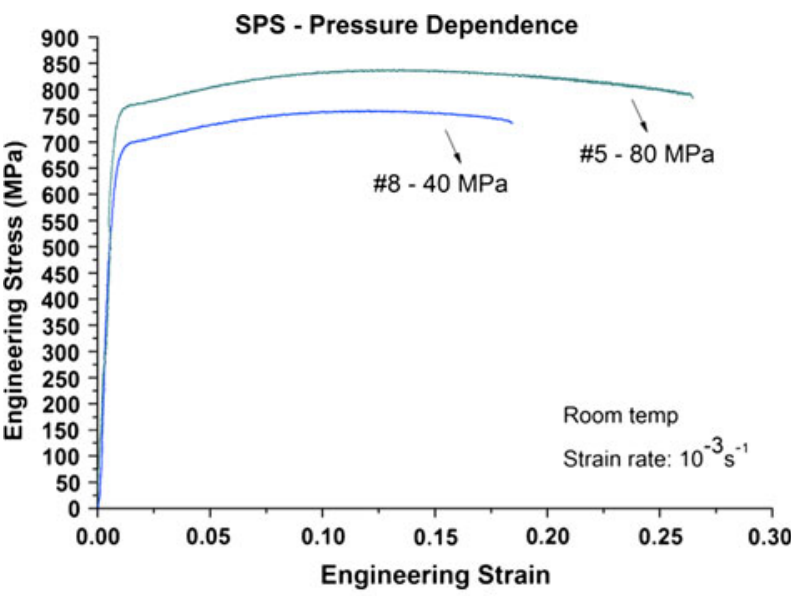

(a)

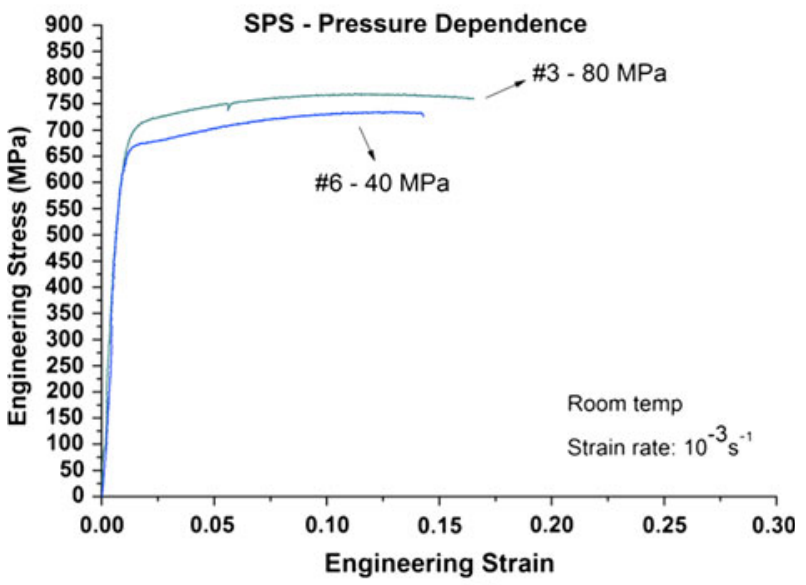

(b)

Fig. 5-Engineering stress-strain curves comparing (a) \#5 and \#8 (dwell time $=5 \mathrm{~min})$ and $(b) \# 3$ and \#6 (dwell time $=3 \mathrm{mins}$ ), to reveal SPS pressure dependence.

approach (i.e., identical heating rate, temperature, and dwell time). Not surprisingly, a higher applied pressure $(80 \mathrm{MPa})$ improved the strength and ductility of samples due to the attained higher density and improved interparticle bonding. These results are consistent with earlier densification discussion and relevant literature, revealing the contribution of a higher applied pressure during SPS. ${ }^{[58,64]}$ In fact, this factor supports the current strategy of using higher pressure-resistant die sets (e.g., steel and tungsten carbide), thereby enabling a higher applied pressure, as illustrated in relevant studies. ${ }^{[20,26]}$

Again, a similar comparative approach was used for the heating rate (i.e., identical pressure, temperature, and dwell time) and dwell time (i.e., identical heating rate, temperature, and pressure) dependence. A lower heating rate of $50 \mathrm{~K} / \mathrm{min}\left(50{ }^{\circ} \mathrm{C} / \mathrm{min}\right)$ was found to improve the properties as compared to a higher heating rate, in different ways when different pressures were applied (i.e., higher strength for $40 \mathrm{MPa}$ applied pressure [Figure 6(b)] and higher ductility for $80 \mathrm{MPa}$ applied pressure [Figure 6(a)]). Both sample \#6 (50 $\left.\mathrm{K} / \mathrm{min} \quad\left[50{ }^{\circ} \mathrm{C} / \mathrm{min}\right]\right)$ and sample \#9 $(100 \mathrm{~K} / \mathrm{min}$ $\left.\left[100{ }^{\circ} \mathrm{C} / \mathrm{min}\right]\right)$ processed using a lower applied pressure exhibited a limited post necking strain as a result of a 


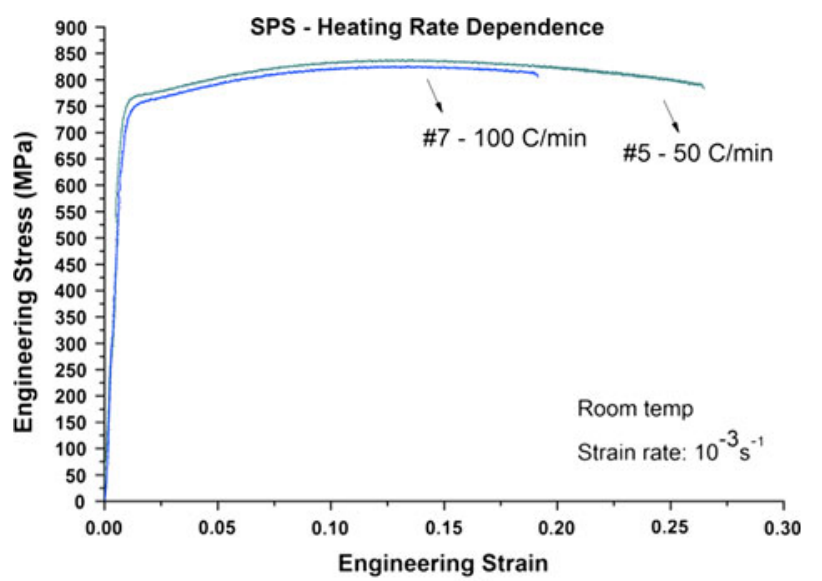

(a)

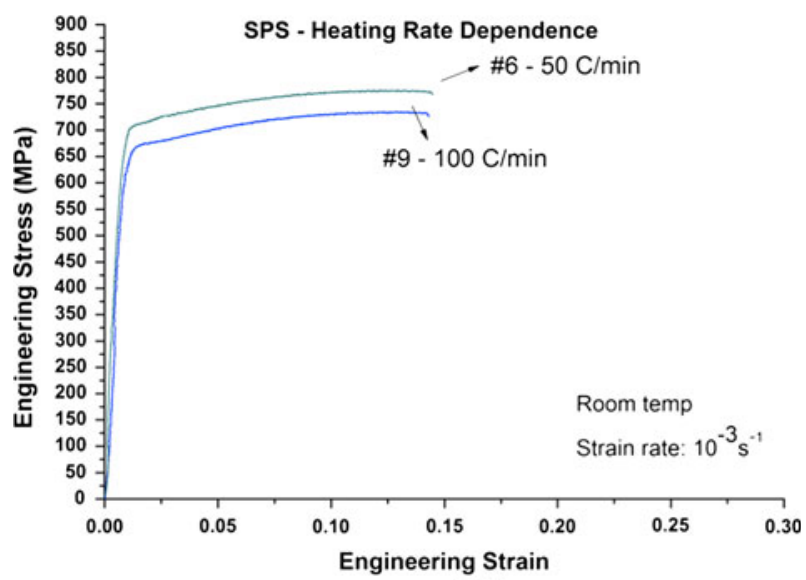

(b)

Fig. 6-Engineering stress-strain curves comparing (a) \#5 and \#7 (pressure $=80 \mathrm{MPa}$ ) and $(b) \# 6$ and $\# 9$ (pressure $=40 \mathrm{MPa}$ ), to reveal SPS pressure dependence.

relatively lower density. The higher strength of \#6 is believed to originate from a possibly inhibited localization of heating at lower heating rates reducing the excessive grain growth and coarsening. However, as explained previously, such localization effects are smaller when a higher applied pressure is used. Accordingly, sample \#7 (100 K/min $\left.\left[100{ }^{\circ} \mathrm{C} / \mathrm{min}\right]\right)$ and \#5 $\left(50 \mathrm{~K} / \mathrm{min}\left[50{ }^{\circ} \mathrm{C} / \mathrm{min}\right]\right)(80 \mathrm{MPa}$ applied pressure for both) exhibit relatively similar tensile behavior. The larger postnecking elongation for \#5 is attributable to a longer total processing time improving particle bonding.

A notably higher strength and ductility was observed for sample \#5 (3 minutes of dwell time) as compared to sample \#3 (5 minutes of dwell time), revealing the dwell time dependence as illustrated in Figure 7. The longer dwell time is thought to cause coarsening and annihilate the nonequilibrium microstructure ${ }^{[65]}$ (characterized by a high interface energy and randomly oriented dislocations at grain boundaries) due to the thermal recovery effect. Significant literature evidence shows the contribution of a nonequilibrium microstructure to dislocation activity, which provides improved strength and ductility in fine-grained structures. ${ }^{[1,66]}$

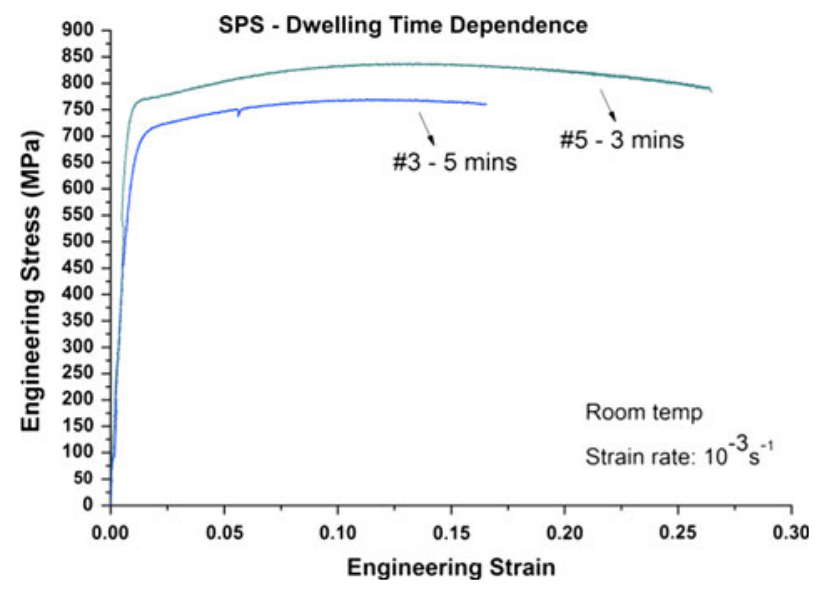

Fig. 7-Engineering stress-strain curves comparing \#3, and \#5, to reveal dwell time dependence.

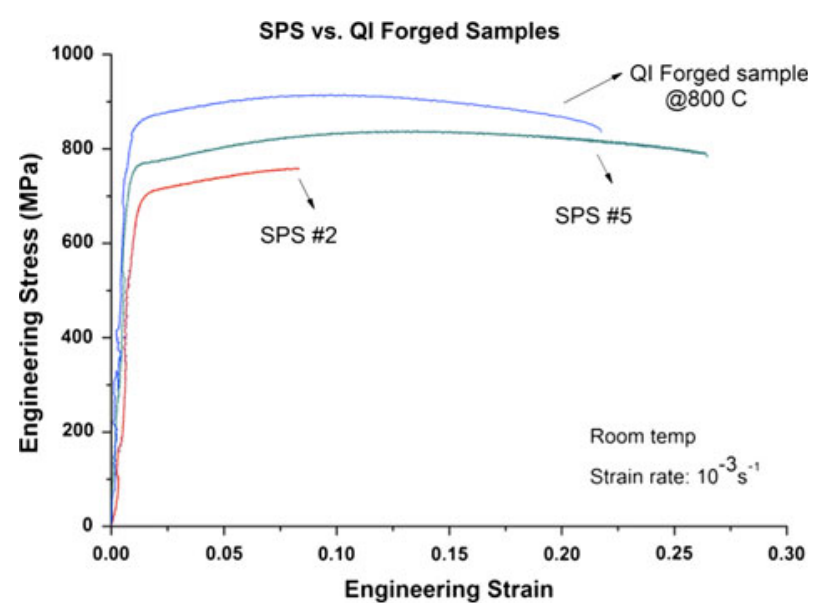

Fig. 8-Engineering stress-strain curves comparing SPS samples with quasi-isostatic forged sample (at $1073 \mathrm{~K}\left[800{ }^{\circ} \mathrm{C}\right]$ ) of same powder composition.

In addition to the comparative SPS data, in Figure 8, selected SPS samples are as compared to an identical test specimen machined from QI forged samples (at $1073 \mathrm{~K}$ $\left[800{ }^{\circ} \mathrm{C}\right]$ ) of the same powder composition (i.e., 70 pct cryomilled +30 pct as-received). ${ }^{[32]}$ In this graph, both sample \#5, which exhibited the best tensile properties among all SPS samples, and sample \#2, which was consolidated at $1073 \mathrm{~K}\left(800{ }^{\circ} \mathrm{C}\right)$ (i.e., same temperature with QI forged sample), are presented as reference materials. The higher strength of the QI forged material is attributable to a further refined microstructure as a result of the deformation introduced ${ }^{[67,68]}$ and the increased interstitial content due to atmospheric contamination between the two forging steps (partially densified sample is exposed to atmosphere at $\sim 800{ }^{\circ} \mathrm{C}$ $[1073 \mathrm{~K}])$. Additional evidence of a refined microstructure in QI forged material includes the lower strain hardening observed during uniform elongation. ${ }^{[69]}$

The higher strength of cryomilled CP-Ti as compared to that of conventionally processed $\mathrm{CP}-\mathrm{Ti}$ is primarily attributable the following factors: a refined microstructure (Hall-Petch mechanism), ${ }^{[62,70]}$ an increased 
interstitial solute concentration, ${ }^{[12,42,60,71]}$ and dislocation strengthening. ${ }^{[62]}$ These factors are not independent from each other because the microstructure formation and deformation in hep Ti has a strong dependence to interstitial solute concentration, as shown in previous studies by Conrad and coworkers. ${ }^{[42,54,72]}$ The FriedelFleischer $^{[71]}$ and Mott-Nabarro ${ }^{[73]}$ models are generally used to explain the isolated solid-solution strengthening effects, which are typically more accurate for coarsegrained structures. However, for cryomilled $\mathrm{Ti}$, the combined effects of obstacles (i.e., solute atoms, dislocation, and grain boundaries) should be considered, along with alternative deformation mechanism (i.e., grain boundary sliding) as all these are influenced by each other. ${ }^{[61,74-76]}$

One of the most conspicuous findings in the current study is the measured high ductility. Elongation to failure values $\sim 30$ pct were measured for samples with high strength (e.g., \#4 and \#5). As mentioned previously, the elimination of extrinsic effects such as porosity or insufficient interparticle bonding is an essential first step. However, even a density near theoretical value and perfect interparticle bonding does not guarantee a high ductility. The intrinsic microstructure governs the deformation and is responsible for the mechanical response to applied loads. As shown in many previous reports, it is hard to retain ductility for high-strength bulk nanostructured metals. ${ }^{[69,77-79]}$ Generally, high strength and good ductility are not present together, and bulk nanostructured metals usually have high strength and disappointingly low ductility. ${ }^{[79]}$ This is due to limited dislocation slip at such a small grain size scale. ${ }^{[63]}$ However, several recent studies report a high ductility in nanostructured and UFG metals, and these studies discuss effective strategies in light of governing deformation mechanisms. ${ }^{[36,37,69]}$ The presence of a bimodal or multimodal structure, twin boundaries, second-phase precipitates, and nonequilibrium grain boundaries have been established as forthcoming factors, which improve ductility in nanostructured and ultrafine-UFG materials without a significant loss in strength. ${ }^{[36]}$ From a mechanistic point of view, all these factors help to attain a large uniform elongation via delaying necking instabilities. Hart's instability criterion ${ }^{[80]}$ suggests that a high strain hardening rate and strain rate sensitivity is essential for delaying necking instabilities. ${ }^{[70,81]}$ Accordingly, necking instability sets when the condition given by the following relation is reached.

$$
\frac{1}{\sigma}\left(\frac{\partial \sigma}{\partial \varepsilon}\right)_{\dot{\varepsilon}}-1+m \leq 0
$$

The first term in this equation is the normalized strain-hardening rate and the term $m$ is the strain rate sensitivity.

In the current study, the formation of a bimodal microstructure attained via blending of as-received coarse grain powders with cryomilled powders, is thought to provide strain hardening and thereby help delaying necking instabilities. A similar approach was previously used for cryomilled materials, including
$\mathrm{Al},{ }^{[15]} \mathrm{Ni}^{\left[{ }^{[39]}\right.}$ and $\mathrm{Ti}^{[13]}$ alloys. A bimodal or multimodal structure can also be formed via thermomechanical treatments and again provide a high ductility. For example, in a related study, Wang et al. ${ }^{[38]}$ reported an improved ductility for high-strength cryorolled $\mathrm{Cu}$ after low-temperature annealing.

The introduction of coarse grains into an ultra-fine and/or nano-grained matrix also represents an effective strategy to suppress crack growth and help retaining fracture toughness as modeled by Ovid'ko and Sheinerman. ${ }^{[35]}$ This is also thought be an additional mechanism for the retained high ductility in SPS-cryomilled CP-Ti materials in the current study.

The strain rate sensitivity $(m)$ of the SPS materials was measured and calculated on the basis of tensile strain rate jump testing results. The true stress vs. true strain curve for strain rate jump tested specimen from sample $\# 5$ is given in Figure 9. Strain rate sensitivity is commonly defined as ${ }^{[63]}$;

$$
m=\left(\frac{\partial \ln \sigma}{\partial \ln \dot{\varepsilon}}\right)_{\varepsilon . T}
$$

Accordingly, $m=0.026$ and $m=0.035$ were calculated at strain rates of $10^{-3} \mathrm{~s}^{-1}$ and $10^{-4} \mathrm{~s}^{-1}$, respectively. These strain rate sensitivity values correspond to a relatively small deformation activation volume $(\sim 12$ $b^{3}$ ). In the relevant literature, the reported values for strain rate sensitivity of fine-grained $\mathrm{Ti}$ are relatively smaller, as compared to cryomilled and SPS CP-Ti. For example, Jia et al. ${ }^{[70]}$ report that $m \sim 0.009$ for UFG CP$\mathrm{Ti}$, which was processed via equal channel angular pressing followed by cold rolling. ${ }^{70]}$

The high strain rate sensitivity measured in the current study is attributable to the presence of grain boundaries with high dislocation content and to the presence of considerable amounts interstitial solute atoms such as $\mathrm{O}$ and $\mathrm{N}$. Similarly, a high ductility in combination with high strength was reported by $\mathrm{Xu}$ et $a .^{[12]}$ for dehydrided Ti with high interstitial content,

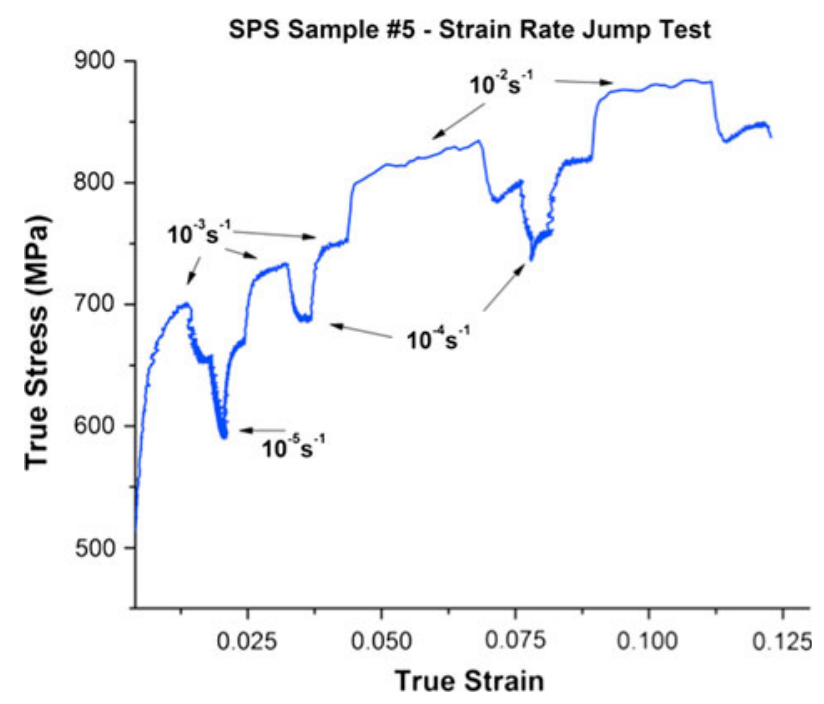

Fig. 9-Room-temperature strain rate jump test plot for sample \#5 revealing the strain rate dependence of deformation. 
where powders were consolidated into bulk samples via a back-pressure equal-channel angular pressing technique. In more detailed studies on the deformation of hcp Ti, it was shown that the controlling mechanism of plastic strain in Ti involves thermally activated dislocations overcoming the obstacles created by impurity atoms. ${ }^{[61,74,82]}$ This is also true for other hep metals such as $\mathrm{Zr}$ and $\mathrm{Hf}$, in which easy slip occurs along the $\{10 \overline{10}\}$ prismatic planes in the $\langle 11 \overline{2} 0\rangle$ direction. ${ }^{[74]}$ Therefore, it is typically independent of grain size and strain, unlike other hep metals in which basal slip is dominant. Consistent with this suggestion, Okazaki and Conrad reported an increased strain rate sensitivity with increasing interstitial solute content for hcp $\mathrm{Ti}^{\left[{ }^{42,72]}\right.}$

Another factor that is thought to be responsible for the measured increase in ductility is the presence of grain boundary sliding. The randomly oriented dislocation activity (as shown in postmortem TEM micrographs in Figure 3) at grain boundary regions of cryomilled and SPS CP-Ti may be a factor facilitating grain boundary sliding, and also leading to a high $m$, as illustrated in previous studies. ${ }^{[81]}$

\section{CONCLUSIONS}

The densification, microstructure evolution, and mechanical response of SPS bimodal (cryomilled + as-received) CP-Ti samples were studied on the basis of starting powder, varied SPS parameters, TEM results, and measured mechanical properties. The primary results are summarized as follows:

1. The use of a high applied pressure during SPS was found to be essential for elimination of consolidation artifacts. Along with applied pressure, a high SPS temperature, short dwell time, and slow heating rate were also found to be beneficial for attaining improved mechanical properties.

2. As compared to the available literature on NS and UFG CP-Ti (i.e., cryomilled + QI forged and severe plastic deformed), materials in the current study exhibited lower YS and UTS but enhanced ductility. The lower strength was attributed to coarser microstructure and relatively low interstitial content (as compared to QI forged CP-Ti). The higher ductility was rationalized on the basis of Hart's criterion (i.e., high strain hardening rate and strain rate sensitivity).

3. The increased solute atom concentration in cryomilled and SPS CP-Ti was reported to have a strong influence on microstructure evolution and deformation (i.e., activation volume). The interaction between the solute atoms and the dislocations were discussed on the basis of measured strain rate sensitivity and previous reports.

\section{ACKNOWLEDGMENTS}

The financial support provided by the Army Research Office (Grant No. W911NF-06-1-0230 and W911NF10-1-0512) is gratefully acknowledged.

\section{OPEN ACCESS}

This article is distributed under the terms of the Creative Commons Attribution Noncommercial License which permits any noncommercial use, distribution, and reproduction in any medium, provided the original author(s) and source are credited.

\section{REFERENCES}

1. M.J. Donachie: Titanium: A Technical Guide, ASM International, Materials Park, OH, 2000.

2. G. Lütjering and J.C. Williams: Titanium, Springer Verlag, New York, NY, 2007.

3. C.N. Elias, J.H.C. Lima, R. Valiev, and M.A. Meyers: JOM, 2008, vol. 60 , pp. 46-49.

4. V.N. Moiseyev: Titanium Alloys: Russian Aircraft and Aerospace Applications, CRC Press, Boca Raton, FL, 2005.

5. M. Geetha, A.K. Singh, R. Asokamani, and A.K. Gogia: Prog. Mater. Sci., 2009, vol. 54, pp. 397-425.

6. R.Z. Valiev, I.P. Semenova, V.V. Latysh, H. Rack, T.C. Lowe, J. Petruzelka, L. Dluhos, D. Hrusak, and J. Sochova: Adv. Eng. Mater., 2008, vol. 10, p. 15.

7. I.P. Semenova, G.K. Salimgareeva, V.V. Latysh, T. Lowe, and R.Z. Valiev: Mater. Sci. Eng. A, 2009, vol. 503, pp. 92-95.

8. A.V. Sergueeva, V.V. Stolyarov, R.Z. Valiev, and A.K. Mukherjee: Scripta Mater., 2001, vol. 45, pp. 747-52.

9. R.K. Islamgaliev, V.U. Kazyhanov, L.O. Shestakova, A.V. Sharafutdinov, and R.Z. Valiev: Mater. Sci. Eng. A, 2008, vol. 493, pp. 190-94.

10. X. Zhao, W. Fu, X. Yang, and T.G. Langdon: Scripta Mater., 2008, vol. 59, pp. 542-45.

11. R.Z. Valiev, R.K. Islamgaliev, and I.V. Alexandrov: Prog. Mater. Sci., 2000, vol. 45, p. 103.

12. W. Xu, X. Wu, D. Sadedin, G. Wellwood, and K. Xia: Appl. Phys. Lett., 2008, vol. 92, p. 011924.

13. O. Ertorer, T. Topping, Y. Li, W. Moss, and E.J. Lavernia: Scripta Mater., 2009, vol. 60, pp. 586-89.

14. O. Ertorer, A. Zúñiga, T. Topping, W. Moss, and E.J. Lavernia: Metall. Mater. Trans. A, 2009, vol. 40A, pp. 91-103.

15. B.O. Han, E.J. Lavernia, Z. Lee, S. Nutt, and D. Witkin: Metall. Mater. Trans. A, 2005, vol. 36A, pp. 957-65.

16. F. Sun, P. Rojas, A. Zúniga, and E.J. Lavernia: Mater. Sci. Eng. A, 2006, vol. 430, pp. 90-97.

17. F. Sun, A. Zúñiga, P. Rojas, and E.J. Lavernia: Metall. Mater. Trans. A, 2006, vol. 37A, pp. 2069-78.

18. J.R. Groza and A. Zavaliangos: Rev. Adv. Mater. Sci, 2003, vol. 5, pp. 24-33.

19. R. Orrù, R. Licheri, A.M. Locci, A. Cincotti, and G. Cao: Mater. Sci. Eng. R, 2009, vol. 63, pp. 127-287.

20. Z.A. Munir, U.A. Tamburini, and M. Ohyanagi: J. Mater. Sci., 2006, vol. 41, pp. 763-77.

21. P. Angerer, L.G. Yu, K.A. Khor, G. Korb, and I. Zalite: J. Eur. Ceram. Soc., 2005, vol. 25, pp. 1919-27.

22. C. Florin and N. Alin: Fascicle of Management and Technology, http://imtuoradea.ro, pp. 809-16.

23. J.R. Groza and A. Zavaliangos: Mater. Sci. Eng. A, 2000, vol. 287, pp. 171-77.

24. V. Mamedov: Powder Metall., 2002, vol. 45, pp. 322-28.

25. D. Handtrack, F. Despang, C. Sauer, B. Kieback, N. Reinfried, and Y. Grin: Mater. Sci. Eng. A, 2006, vol. 437, pp. 423-29.

26. M. Tokita: New Ceram., 1994, vol. 7, pp. 63-74.

27. M. Tokita: Mater. Sci. Forum, 1999, vols. 308-311, pp. 83-88.

28. J.R. Groza, M. Garcia, and J. Schneider: J. Mater. Res., 2001, vol. 16 , pp. $286-92$

29. D.M. Hulbert, A. Anders, J. Andersson, E.J. Lavernia, and A.K. Mukherjee: Scripta Mater., 2009, vol. 60, pp. 835-38.

30. J. Ye, L. Ajdelsztajn, and J.M. Schoenung: Metall. Mater. Trans. $A$, 2006, vol. 37A, pp. 2569-79.

31. Z. Zhang, B.Q. Han, J.Y. Huang, Y.H. Han, Y. Zhou, K. Kakegawa, and E.J. Lavernia: Metall. Mater. Trans. A, 2009, vol. 40 A, pp. 2023-29. 
32. O. Ertorer, unpublished research, University of California, Davis, 2009.

33. C. Suryanarayana: Prog. Mater. Sci., 2001, vol. 46, pp. 1-184.

34. V.L. Tellkamp, E.J. Lavernia, and A. Melmed: Metall. Mater. Trans. A, 2001, vol. 32A, pp. 2335-43.

35. I.A. Ovid'ko and A.G. Sheinerman: Rev. Adv. Mater. Sci., 2007, vol. 16 , pp. $1-9$.

36. E. Ma: JOM, 2006, vol. 58, pp. 49-53.

37. Y.T. Zhu and X. Liao: Nature Mater., 2004, vol. 3, pp. 351-52.

38. Y. Wang, M. Chen, F. Zhou, and E. Ma: Nature, 2002, vol. 419, pp. $912-15$

39. Y. Zhao, T. Topping, J.F. Bingert, J.J. Thornton, A.M. Dangelewicz, Y. Li, W. Liu, Y. Zhu, Y Zhou, and E.J. Lavernia: Adv. Mater., 2008, vol. 20, pp. 3028-33.

40. O. Ertorer, T.D. Topping, Y. Li, Y.H. Zhao, W. Moss, and E.J. Lavernia: Mater. Sci. Forum, 2009, vols. 633-634, pp. 459-69.

41. D.B. Witkin and E.J. Lavernia: Prog. Mater. Sci., 2006, vol. 51, pp. 1-60.

42. H. Conrad: Prog. Mater. Sci., 1981, vol. 26, pp. 123-403.

43. H. Gleiter: Phys. Status Solidi (b), 2006, vol. 172, pp. 41-51.

44. Y.R. Kolobov: Grain Boundary Diffusion and Properties of Nanostructured Materials, Cambridge International Science Publishing, Cambridge, UK, 2007.

45. N.L. Peterson: Int. Mater. Rev., 1983, vol. 28, pp. 65-91.

46. M.P. Seah: J. Phys. F: Met. Phys., 1980, vol. 10, pp. 1043-64.

47. T. Xu and S. Song: Acta Metall., 1989, vol. 37, pp. 2499-506.

48. B.Q. Han, Z. Zhang, and E.J. Lavernia: Phil. Mag. Lett., 2005, vol. 85 , pp. $97-108$.

49. J. Lee, F. Zhou, K.H. Chung, E.J. Lavernia, and N.J. Kim: Metall. Mater. Trans. A, 2001, vol. 32A, pp. 3109-15.

50. T.H. De Keijser, J.I. Langford, E.J. Mittemeijer, and A.B.P. Vogels: J. Appl. Crystall., 1982, vol. 15, pp. 308-14.

51. F.A. Mohamed: Acta Mater., 2003, vol. 51, pp. 4107-19.

52. T.G. Nieh and J. Wadsworth: Scripta Metall. Mater., 1991, vol. 25 , pp. $955-58$

53. F.J. Gil and J.A. Planell: Mater. Sci. Eng. A, 2000, vol. 283, pp. 17-24.

54. K. Okazaki and H. Conrad: Metall. Trans. B, 1972, vol. 3, pp. 2411-21.

55. S.J.L. Kang: Sintering: Densification, Grain Growth, and Microstructure, Butterworth-Heinemann, Boston, MA, 2005.

56. R.M. German: Sintering Theory and Practice, John Wiley \& Sons Inc., New York, NY, 1996.
57. C. Shearwood, Y.Q. Fu, L. Yu, and K.A. Khor: Scripta Mater., 2005, vol. 52, pp. 455-60.

58. M. Omori: Mater. Sci. Eng. A, 2000, vol. 287, pp. 183-88.

59. A.R. Von Hippel and S.O. Morgan: J. Electrochem. Soc., 1955, vol. 102 , p. 68 C.

60. J. Kratochvil and H. Conrad: Scripta Metall., 1970, vol. 4, pp. 815-24.

61. V.A. Moskalenko, V.D. Natsik, and V.N. Kovaleva: Low Temp. Phys., 2005, vol. 31, p. 907.

62. T.H. Courtney: Mechanical Behavior of Materials, McGraw-Hill, New York, NY, 1990.

63. M.A. Meyers, A. Mishra, and D.J. Benson: Prog. Mater. Sci., 2006, vol. 51, pp. $427-556$

64. Z.H. Zhang, F.C. Wang, S.K. Lee, Y. Liu, J.W. Cheng, and Y. Liang: Mater. Sci. Eng. A, 2009, vol. 523A, pp. 134-38.

65. A.A. Nazarov, A.E. Romanov, and R.Z. Valiev: Acta Metall. Mater., 1993, vol. 41, pp. 1033-40.

66. R.Z. Valiev, R.K. Islamgaliev, N.F. Kuzmina, Y. Li, and T.G. Langdon: Scripta Mater., 1998, vol. 40, pp. 117-22.

67. A.P. Newbery, B. Ahn, R.W. Hayes, P.S. Pao, S.R. Nutt, and E.J. Lavernia: Metall. Mater. Trans. A, 2008, vol. 39A, pp. 2193-205.

68. J.R. Groza: J. Mater. Eng. Perf., 1993, vol. 2, pp. 283-90.

69. E. Ma: Nature Mater., 2003, vol. 2, pp. 7-8.

70. D. Jia, Y.M. Wang, K.T. Ramesh, E. Ma, Y.T. Zhu, and R.Z. Valiev: Appl. Phys. Lett., 2001, vol. 79, p. 611.

71. R.L. Fleischer: Acta Metall., 1961, vol. 9, pp. 996-1000.

72. K. Okazaki and H. Conrad: Acta Metall., 1973, vol. 21, pp. 1117-29.

73. F.R.N. Nabarro: Philos. Mag., 1977, vol. 35A, pp. 613-22.

74. P. Rodriguez: Metall. Mater. Trans. A, 2004, vol. 35A, pp. 2697705

75. M.J. Zehetbauer and Y.T. Zhu: Bulk Nanostructured Materials, Wiley Vch, Weinheim, Germany, 2009.

76. T. Tanaka and H. Conrad: Acta Metall., 1972, vol. 20, pp. 1019-29.

77. Y.H. Zhao, X.Z. Liao, S. Cheng, E. Ma, and Y.T. Zhu: $A d v$. Mater., 2006, vol. 18, pp. 2280-83.

78. R. Valiev: Nature Mater., 2004, vol. 3, pp. 511-16.

79. C.C. Koch: Scripta Mater., 2003, vol. 49, pp. 657-62.

80. E.W. Hart: Acta Metall., 1967, vol. 15, pp. 351-55.

81. E. Ma: Scripta Mater., 2003, vol. 49, pp. 663-68.

82. V.V. Shpeı̌zman, V.I. Nikolaev, N.N. Peschanskaya, A.E. Romanov, B.I. Smirnov, I.A. Aleksandrov, N.A. Enikeev, V.U. Kazykhanov, and A.A. Nazarov: Phys. Solid State, 2007, vol. 49, pp. $678-83$. 